\title{
Resveratrol alleviates obesity-associated podocyte injury in ovariectomized obese rats
}

\author{
BING LI $^{1,2 *}$, XIAOYAN XIAO ${ }^{1 *}$, YULIAN MIAO ${ }^{3}$, LING GUO $^{1}$, \\ JUNHUI ZHEN $^{4}$, XIANHUA LI ${ }^{1}$, BEI JIANG ${ }^{1}$ and ZHAO HU ${ }^{1}$ \\ ${ }^{1}$ Department of Nephrology, Qilu Hospital of Shandong University, Jinan, Shandong 250012; ${ }^{2}$ Department of \\ Nephrology, Qilu Hospital of Shandong University Qing-Dao, Qingdao, Shandong 266000; ${ }^{3}$ Department of \\ Medical Administration, Weifang Traditional Chinese Medicine Hospital, Weifang, Shandong 261041; \\ ${ }^{4}$ Department of Pathology, Qilu Hospital of Shandong University, Jinan, Shandong 250012, P.R. China
}

Received April 29, 2018; Accepted October 22, 2019

DOI: $10.3892 / \mathrm{etm} .2019 .8178$

\begin{abstract}
Obesity-associated podocyte injury increases in parallel with inflammatory responses. Resveratrol, as an anti-inflammatory and antioxidative agent, has been proven to be effective in obesity. The purpose of the present study was to investigate the function of resveratrol in the early stages of podocyte injury in ovariectomized rats fed a high-fat diet (HFD). The 3-month-old female Wistar rats were randomly divided into four groups: Sham operation with a standard diet; sham operation with a HFD; ovariectomy with a HFD $(\mathrm{O}+\mathrm{H})$; and ovariectomy plus HFD treatment with resveratrol $(40 \mathrm{mg} / \mathrm{kg} / \mathrm{day})(\mathrm{O}+\mathrm{H}+\mathrm{R})$. Following 12 weeks, the weights of the rats were measured and serum was obtained to measure the levels of $17 \beta$-estradiol (E2), serum lipids, serum creatinine, fasting blood glucose (FBG) and insulin. Periodic acid-schiff staining was used to detect renal pathological changes. Meanwhile, the expression of the podocyte-associated proteins nephrin and Wilms' tumor-1 was investigated using immunohistochemical staining, and the levels of tumor necrosis factor- $\alpha$, interleukin- 6 and monocyte chemotactic protein-1 in renal tissues were determined using
\end{abstract}

Correspondence to: Professor Bei Jiang, Department of Nephrology, Qilu Hospital of Shandong University, 107 Wenhua Xi Road, Jinan, Shandong 250012, P.R. China

E-mail: qilujiangbei@sdu.edu.cn

*Contributed equally

Abbreviations: E2, 17 $\beta$-estradiol; SCr, serum creatinine; TC, total cholesterol; TG, triglyceride; LDL-C, low-density lipoprotein cholesterol; FBG, fasting blood glucose; HOMA-IR, homeostasis model assessment of insulin resistance; TNF- $\alpha$, tumor necrosis factor- $\alpha$; IL-6, interleukin 6; MCP-1, monocyte chemotactic protein-1; WT-1, Wilms' tumor-1; HFD, high-fat diet; PAS, periodic acidschiff

Key words: resveratrol, obesity, podocyte, inflammation, nephrin, Wilms' tumor-1 western blotting. Compared with the $\mathrm{O}+\mathrm{H}$ group, resveratrol significantly reduced the body weight, serum levels of total cholesterol, low-density lipoprotein cholesterol, FBG and insulin resistance, and increased the levels of E2 in obese rats with an ovariectomy combined with an HFD $(\mathrm{P}<0.05)$. Compared with the $\mathrm{O}+\mathrm{H}$ group, although the $\mathrm{O}+\mathrm{H}+\mathrm{R}$ group had no significant changes in renal pathology, the changes in the levels of podocyte-associated proteins and inflammatory markers were significantly reversed $(\mathrm{P}<0.05)$. These results suggest that resveratrol may attenuate early podocyte injury by improving lipid metabolism and insulin sensitivity, and subsequently inhibiting inflammatory responses in obese rats induced by an ovariectomy with a HFD.

\section{Introduction}

Obesity is increasing globally and is a potential risk factor for metabolic syndrome, which is associated with insulin resistance, blood lipid disorders and hypertension $(1,2)$. Furthermore, the epidemic of obesity, independently of diabetes and hypertension, has resulted in an increased incidence of obesity-associated glomerulopathy, which is defined morphologically as glomerulomegaly with or without focal segmental glomerulosclerosis (3-5). Chronic-grade inflammation is markedly observed in obesity (2), which may induce podocyte damage, and further cause proteinuria and renal injury.

It is well-known that estrogen participates in the regulation of the physiological processes of the human body in women, and estrogen deficiency increases the susceptibility of postmenopausal women to metabolic disorders including obesity, osteoporosis, cardiovascular disease and chronic kidney disease (CKD) (6-8). Numerous studies have suggested that decreasing the biosynthesis of estrogen in ovariectomized animals or menopausal women results in inflammatory cell infiltration and the production of inflammatory cytokines, which are associated with an increased incidence of CKD (9-11).

Natural products derived from plants have long been used in the treatment of lifestyle-associated diseases, including obesity $(12,13)$. Traditional Chinese Medicine has been used 
as a conventional or complementary therapy for the treatment of renal injury $(14,15)$. It has previously been reported that natural products such as poricoic acid, are able to inhibit renal fibrosis by regulating the tumor growth factor $\beta$ (TGF- $\beta$ )/Smad signaling pathway (16-19). Resveratrol (trans-3,5,4-trihydroxystilbene) is a natural polyphenol with antioxidant and anti-inflammatory properties (20) which is produced in a myriad of plants including grapes, berries, peanuts and other traditional Chinese medicinal plants. It has been reported to be effective in preventing the development of a number of diseases including cardiovascular disease $(21,22)$, diabetes (23), cancer (24), memory deficit (25) and functional gastrointestinal dyspepsia (26). Several studies have revealed that resveratrol has anti-obesity activity $(13,27,28)$. Although resveratrol protects against the development of obesity-associated renal damage, the underlying mechanisms are not fully clear. The present study established an obese rat model via an ovariectomy and a high-fat diet (HFD), and investigated the function of resveratrol in the early stages of podocyte injury in this model.

\section{Materials and methods}

Chemicals and reagents. Resveratrol (purity >98\%; cat. no. 0810018-22) was purchased from Sigma-Aldrich (Merck KGaA, Darmstadt, Germany). High-fat feed (1\% cholesterol, $10 \%$ lard, $0.1 \%$ cholate and $88.9 \%$ basic feeding product, cat. no. SCXK 2009-0012) was purchased from Keaoxieli Feed Co., Ltd. (Beijing, China). The primary antibodies used in the present study were: Rabbit anti-tumor necrosis factor $\alpha$ (TNF- $\alpha$; cat. no. ab9755), rabbit anti-interleukin 6 (IL-6; cat. no. ab25107), rabbit anti-monocyte chemotactic protein-1 (MCP-1; cat. no. ab25124), rabbit anti-nephrin (cat. no. ab136894) and rabbit anti-Wilms' tumor-1 (WT-1; cat. no. ab180840) (all from Abcam, Cambridge, MA, USA). GAPDH polyclonal antibody (cat. no. 10494-1-AP) was purchased from ProteinTech Group, Inc. (Chicago, IL, USA). Horseradish peroxidase-conjugated Affinipure goat anti-rabbit immunoglobulin $\mathrm{G}$ ( $\mathrm{IgG}$ ) secondary antibodies (cat. no. ZB2301) were obtained from OriGene Technologies, Inc. (Rockville, MD, USA).

Animals and different treatments. A total of 40 female

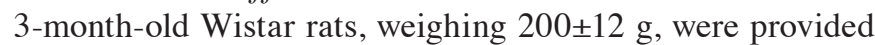
by Shandong University Laboratory Animal Center (Jinan, China). Rats were housed at standard conditions of temperature $\left(20 \pm 2^{\circ} \mathrm{C}\right)$ and humidity $(50-70 \%)$ under a 12-h light/dark cycle (lights on at 7:00 a.m.) with ad libitum access to food and water. A rat model of kidney function and structure changes was intervened by ovariectomy combined with a HFD (11). Following one week of acclimatization, the rats were randomly divided into four groups ( $\mathrm{n}=10$ per group): Sham operation with a standard diet $(\mathrm{S}+\mathrm{N})$; sham operation with a $\mathrm{HFD}(\mathrm{S}+\mathrm{H})$; ovariectomy with a HFD $(\mathrm{O}+\mathrm{H})$; ovariectomy plus a $\mathrm{HFD}$ treated with resveratrol $(\mathrm{O}+\mathrm{H}+\mathrm{R})$. Rats in the aforementioned four groups were anesthetized with sodium pentobarbital (50 mg/kg body weight; intraperitoneal). They all underwent either a sham surgery or bilateral ovariectomy. Following the surgery, the rats were fed using a standard diet or HFD. Rats were administered resveratrol or sodium carboxymethyl cellulose in their food with a daily dosage of $40 \mathrm{mg} / \mathrm{kg} /$ day for 12 weeks (29). Body weights were measured once a week. All animal procedures were ethically approved by the Animal Ethics Committee of Shandong University (Shandong, China). Symptoms such as unwieldy body affecting their daily activities were set as the humane endpoints for the present study. However, no animal was sacrificed prior to the completion of the experiment as a result of displaying similar symptoms. All efforts were made to minimize animal suffering and stress during the experiments.

Blood and kidney sample preparation. Three months later, owing to surgery or infection, 7 to 9 rats survived in each group. At the end of the experiment, the remaining rats were reserved for overnight fasting with water available. The rats were then anesthetized using sodium pentobarbital $(50 \mathrm{mg} / \mathrm{kg}$ body weight) by an intraperitoneal injection, and blood was collected from the femoral artery. Serum was collected by centrifugation at $1,048 \mathrm{x}$ g at $4^{\circ} \mathrm{C}$ for $15 \mathrm{~min}$, and stored at $-80^{\circ} \mathrm{C}$ until assayed. The rats were then sacrificed by decapitation under deep anesthesia. The bilateral kidneys were rapidly removed and dissected on ice. Portions of the kidneys were snap-frozen in liquid nitrogen and stored at $-80^{\circ} \mathrm{C}$ for protein isolation. An additional portion was fixed in $4 \%$ paraformaldehyde at $4^{\circ} \mathrm{C}$ for $24 \mathrm{~h}$ before histopathologic observation.

Biochemical assays of serum. The serum levels of $17 \beta$-estradiol (E2) were detected using an iodine $\left({ }^{125} \mathrm{I}\right)$ estradiol radioimmunoassay kit (Tianjin Jiuding Medical Bio-Engineering Co., Ltd.) according to the manufacturer's protocol. The serum total cholesterol (TC), triglycerides (TG), low-density lipoprotein cholesterol (LDL-C), serum creatinine ( $\mathrm{SCr}$ ) and fasting blood glucose (FBG) levels were measured using a DVI-1650 automatic biochemistry and analysis instrument (Bayer, Pittsburgh, PA, USA). Serum insulin levels were measured using insulin enzyme-linked immunosorbent assay kits (cat. no. DY8056-05, R\&D Systems, Inc., Minneapolis, MN, USA) according to the manufacturer's protocol. The homeostasis model assessment of insulin resistance (HOMA-IR) was calculated via the following formula: FBG $x$ insulin/22.5.

Histological analysis. The kidneys were excised, and sections were fixed in $10 \%$ formaldehyde at room temperature for $24 \mathrm{~h}$ and embedded in paraffin and cut into 3-5 $\mu \mathrm{m}$-thick sections for light microscopy. Prior to dyeing, following heating at $60^{\circ} \mathrm{C}$ for $20 \mathrm{~min}$, paraffin in the section was removed using xylene before rehydration with absolute ethanol and subsequently 95, 85 and $75 \%$ ethanol gradients for 5 min each and finally added to distilled water. At room temperature, the sections which had been placed into distilled water were stained using hematoxylin-eosin (H\&E; dyed with hematoxylin aqueous solution for $7 \mathrm{~min}$ and eosin for 2-3 $\mathrm{min}$ ), periodic acid-Schiff (PAS; oxygenation with $1 \%$ periodic acid for $10-15 \mathrm{~min}$ and colored in Schiff's solution for 10-30 min) and Masson's trichrome (immersed in Masson complex solution for $\sim 5 \mathrm{~min}$, $2.5 \%$ phosphomolybdic acid for $\sim 5 \mathrm{~min}$ and aniline blue for $\sim 5$ min). Subsequent to dehydration in 75,85 and $95 \%$ ethanol then absolute ethanol gradients for 2 min before washing using xylene and sealing by gum, the sections were observed under a light microscope at a x400 magnification. 
Immunohistochemical analysis. At room temperature, the kidney tissue sections (3-5 $\mu \mathrm{m})$ were deparaffinized by soaking in xylene for $20 \mathrm{~min}$ after heating at $60^{\circ} \mathrm{C}$ for $20 \mathrm{~min}$, rehydrated with 100, 95, 90 and $80 \%$ ethanol gradients for $5 \mathrm{~min}$ and then washed three times with phosphate buffered saline (PBS). Antigen retrieval was performed through incubation in $0.01 \mathrm{M}$ sodium citrate buffer ( $\mathrm{pH} \mathrm{6.0)}$ ) at $95^{\circ} \mathrm{C}$ for $15 \mathrm{~min}$. Subsequent to cooling to room temperature, the slides were washed three times with PBS and then immersed in $0.1 \%$ Triton X-100 for another $15 \mathrm{~min}$. Following that, the slides were incubated in $3 \%$ hydrogen peroxide at room temperature for $10 \mathrm{~min}$ and subsequently placed in blocking buffer (10\% goat serum) for $1 \mathrm{~h}$ at $37^{\circ} \mathrm{C}$. The primary antibodies anti-nephrin (1:150) and anti-WT-1 (1:100), were applied overnight at $4^{\circ} \mathrm{C}$, while the negative control sections were incubated with PBS instead of the primary antibody overnight at $4^{\circ} \mathrm{C}$. All sections were washed three times with PBS and incubated with horseradish peroxidase-conjugated goat anti-rabbit antibodies (1:500) for $1 \mathrm{~h}$ at room temperature, and stained with 3,3'-diaminobenzidine and hematoxylin for $60 \mathrm{~min}$ at $37^{\circ} \mathrm{C}$. The stained slides were observed by light microscopy (magnification, $\mathrm{x} 400$ ), and brown areas were regarded as positive. The colored sections were graded semi-quantitatively (Leica QWin V3 image analysis software; Leica Microsystems $\mathrm{GmbH}$, Wetzlar, Germany) Two specimens were randomly selected in each group and 10 high-power fields per specimen were observed Each score primarily reflected the extent of staining, rather than the intensity, and depended on the percentage of positive areas: No staining or $<5 \%=0 ; 5-25 \%=1 ; 26-50 \%=2 ; 51-75 \%=3$; and $>75 \%=4$.

Western blotting. Tissues were homogenized in a lysis buffer (Beijing Solarbio Science \& Technology Co., Ltd., Beijing, China; cat. no. R0020) and were centrifuged at $12,000 \mathrm{x} \mathrm{g}$ for $20 \mathrm{~min}$ at $4^{\circ} \mathrm{C}$ to collect the supernatant for protein quantification. The concentration of protein was determined using the Pierce Bicinchoninic Acid protein assay kit (Beyotime Institute of Biotechnology, Shanghai, China). A total of $20 \mu \mathrm{g}$ proteins of each sample were resolved on $10 \%$ SDS-PAGE gels, and the proteins were transferred to nitrocellulose membranes. Subsequent to blocking with 5\% non-fat milk at room temperature for $1 \mathrm{~h}$, the membranes were incubated with the primary antibodies anti-TNF- $\alpha(1: 2,000)$, anti-IL-6 $(1: 1,000)$, anti-MCP-1 $(1: 2,000)$ and anti-GAPDH $(1: 5,000)$ overnight at $4^{\circ} \mathrm{C}$. Then, the membranes were incubated with the secondary antibodies (goat anti-rabbit IgG; 1:10,000) at room temperature for $60 \mathrm{~min}$. Finally, proteins were visualized with enhanced chemiluminescence substrate (Pierce; Thermo Fisher Scientific, Inc., Waltham, MA, USA) and exposed to film in a dark room. The quantification of protein density was performed using Image J software (version 1.45; National Institutes of Health, Bethesda, MD, USA). GAPDH was used as a loading control and the relative quantities were obtained by the ratio of protein quantity to GAPDH, and the mean value was obtained.

Statistical analysis. All data are expressed as the mean \pm standard deviation. Statistical analysis was performed using SPSS 20.0 software (IBM Corp., Armonk, NY, USA). Single comparisons were performed using a Student's t-test and multiple comparisons by a two-way analysis of variance with post-hoc least significant difference tests for comparisons where appropriate. $\mathrm{P}<0.05$ was considered to indicate a statistically significant difference.

\section{Results}

Resveratrol affects body weight and serum E2, TC and LDL-C levels in ovariectomized rats with a HFD. Body weight was measured at the beginning of the experiment, and exhibited no significant difference among all groups $(\mathrm{S}+\mathrm{N}, 201 \pm 10 \mathrm{~g}$; $\mathrm{S}+\mathrm{H}, 201 \pm 8 \mathrm{~g} ; \mathrm{O}+\mathrm{H}, 200 \pm 13 \mathrm{~g} ; \mathrm{O}+\mathrm{H}+\mathrm{R}, 198 \pm 11 \mathrm{~g} ; \mathrm{P}>0.05)$. At the end of the experiment, the body weight in the $\mathrm{O}+\mathrm{H}$ group was significantly higher compared with those of the $\mathrm{S}+\mathrm{N}$ and $\mathrm{S}+\mathrm{H}$ groups $(\mathrm{P}<0.05)$. However, the final body weight in the $\mathrm{O}+\mathrm{H}+\mathrm{R}$ group was significantly decreased compared with that in the $\mathrm{O}+\mathrm{H}$ group $(\mathrm{P}<0.05$; Fig. 1$)$.

To assess whether the ovariectomy operation and hyperlipidemic rat model establishment were successful, serum E2, TC, TG, LDL-C and SCr levels were monitored. As presented in Table I, serum E2 levels in the $\mathrm{O}+\mathrm{H}$ group were significantly lower compared with those in the $\mathrm{S}+\mathrm{N}$ and $\mathrm{S}+\mathrm{H}$ groups $(\mathrm{P}<0.05)$. Subsequent to 3 months of treatment with resveratrol, the $\mathrm{E} 2$ levels in the $\mathrm{O}+\mathrm{H}+\mathrm{R}$ group were significantly higher compared with that in the $\mathrm{O}+\mathrm{H}$ group $(\mathrm{P}<0.05)$. Serum TC and LDL-C levels in the $\mathrm{S}+\mathrm{H}$ and $\mathrm{O}+\mathrm{H}$ groups were significantly higher compared with those in the $\mathrm{S}+\mathrm{N}$ group $(\mathrm{P}<0.05)$. However, serum TC and LDL-C levels significantly reduced in the $\mathrm{O}+\mathrm{H}+\mathrm{R}$ group compared with the $\mathrm{O}+\mathrm{H}$ group $(\mathrm{P}<0.05)$. There was no significant difference in serum $\mathrm{TG}$ and $\mathrm{SCr}$ levels among all groups $(\mathrm{P}>0.05)$.

Resveratrol improves insulin sensitivity in ovariectomized rats with an HFD. The effect of resveratrol on metabolic parameters in obese rats was evaluated by testing serum FBG and insulin, and calculating the HOMA-IR. As Fig. 2 reveals, FBG, serum insulin and HOMA-IR were significantly increased in the $\mathrm{O}+\mathrm{H}$ group compared with the $\mathrm{S}+\mathrm{N}$ and $\mathrm{S}+\mathrm{H}$ groups $(\mathrm{P}<0.05)$. Notably, FBG, serum insulin and HOMA-IR were significantly decreased in the $\mathrm{O}+\mathrm{H}+\mathrm{R}$ group compared with the $\mathrm{O}+\mathrm{H}$ group $(\mathrm{P}<0.05)$.

Effects of resveratrol on podocyte injury and renal pathology. In order to investigate whether resveratrol protects against podocyte injury, WT-1 and nephrin expression levels were detected using immunohistochemical analysis as they are specific markers of podocytes $(30,31)$. Nephrin and WT-1 were primarily expressed in the podocytes of the $\mathrm{S}+\mathrm{N}$ group. The expression of nephrin and WT-1 were significantly decreased in the $\mathrm{O}+\mathrm{H}$ group compared with that in the $\mathrm{S}+\mathrm{N}$ group $(\mathrm{P}<0.05$; Fig. 3). However, subsequent to treatment with resveratrol for 12 weeks, these expression changes were significantly reversed in the $\mathrm{O}+\mathrm{H}+\mathrm{R}$ group compared with the $\mathrm{O}+\mathrm{H}$ group $(\mathrm{P}<0.05)$. No significant pathological changes in any group were observed by PAS staining (Fig. 4), H\&E staining or Masson staining (data not shown).

Effects of resveratrol on renal inflammatory cytokine levels. To investigate the effect of resveratrol on renal inflammation, the present study investigated the expression of 
Table I. Effects of resveratrol on serum E2, TC, TG, LDL-C and SCr in all rats.

\begin{tabular}{lcccc}
\hline & \multicolumn{2}{c}{ Animal groups } \\
\cline { 2 - 4 } & $\mathrm{S}+\mathrm{N}(\mathrm{n}=9)$ & $\mathrm{S}+\mathrm{H}(\mathrm{n}=9)$ & $\mathrm{O}+\mathrm{H}(\mathrm{n}=7)$ & $\mathrm{O}+\mathrm{H}+\mathrm{R}(\mathrm{n}=8)$ \\
\hline $\mathrm{E} 2(\mathrm{pg} / \mathrm{ml})$ & $15.04 \pm 1.74$ & $14.36 \pm 2.31$ & $8.00 \pm 1.89^{\mathrm{a}, \mathrm{b}}$ & $11.38 \pm 2.34^{\mathrm{c}}$ \\
TG $(\mathrm{mmol} / \mathrm{l})$ & $1.54 \pm 0.43$ & $1.56 \pm 0.36$ & $1.63 \pm 0.35$ & $1.44 \pm 0.39$ \\
TC $(\mathrm{mmol} / \mathrm{l})$ & $1.62 \pm 0.28$ & $2.25 \pm 0.49^{\mathrm{a}}$ & $2.93 \pm 0.56^{\mathrm{a}, \mathrm{b}}$ & $2.28 \pm 0.14^{\mathrm{c}}$ \\
LDL-C (mmol/l) & $0.17 \pm 0.05$ & $0.25 \pm 0.05^{\mathrm{a}}$ & $0.27 \pm 0.03^{\mathrm{a}}$ & $0.25 \pm 0.06^{\mathrm{c}}$ \\
SCr (umol/l) & $46.8 \pm 4.66$ & $48.6 \pm 2.86$ & $50.3 \pm 5.63$ & $52 \pm 3.55$ \\
\hline
\end{tabular}

$\mathrm{S}+\mathrm{N}$, sham-operation with standard diet group, $\mathrm{S}+\mathrm{H}$, sham-operation with high-fat diet group, $\mathrm{O}+\mathrm{H}$, ovariectomy with high-fat diet group, $\mathrm{O}+\mathrm{H}+\mathrm{R}$, ovariectomy plus high-fat diet treated with resveratrol group; E2, 17 $\beta$-estradiol; TG, triglycerides; TC, total cholesterol; LDL-C, low-density lipoprotein cholesterol; $\mathrm{SCr}$, serum creatinine. ${ }^{\mathrm{a}} \mathrm{P}<0.05$ compared with $\mathrm{S}+\mathrm{N}$ group, ${ }^{\mathrm{b}} \mathrm{P}<0.05$ compared with $\mathrm{S}+\mathrm{H}$ group, ${ }^{\mathrm{c}} \mathrm{P}<0.05$ compared with $\mathrm{O}+\mathrm{H}$ group.

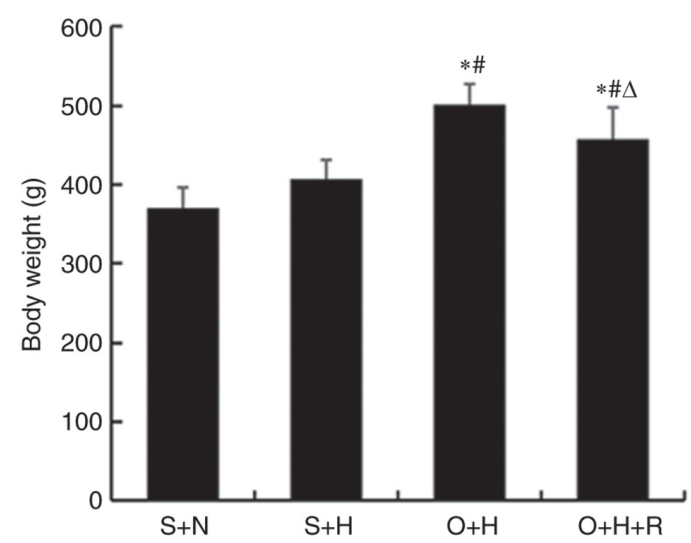

Figure 1. Body weight of rats in different groups. Data were presented as the mean \pm standard deviation ( $\mathrm{n}=7-9$ per group). $\mathrm{S}+\mathrm{N}$, sham-operation with standard diet, $\mathrm{S}+\mathrm{H}$, sham-operation with high-fat diet, $\mathrm{O}+\mathrm{H}$, ovariectomy with high-fat diet, $\mathrm{O}+\mathrm{H}+\mathrm{R}$, ovariectomy plus high-fat diet treated with resveratrol. ${ }^{*} \mathrm{P}<0.05$ vs. $\mathrm{S}+\mathrm{N}$ group, ${ }^{*} \mathrm{P}<0.05$ vs. $\mathrm{S}+\mathrm{H}$ group, ${ }^{\Delta} \mathrm{P}<0.05$ vs. $\mathrm{O}+\mathrm{H}$ group.

inflammation-associated cytokines, including TNF- $\alpha$, IL-6 and MCP-1, by western blotting. The expression levels of these cytokines were significantly increased in the $\mathrm{O}+\mathrm{H}$ group compared with that in the $\mathrm{S}+\mathrm{N}$ group and $\mathrm{S}+\mathrm{H}$ group $(\mathrm{P}<0.05$; Fig. 5). As expected, resveratrol treatment significantly reduced the expression of these inflammatory cytokines in the $\mathrm{O}+\mathrm{H}+\mathrm{R}$ group compared with the $\mathrm{O}+\mathrm{H}$ group $(\mathrm{P}<0.05)$.

\section{Discussion}

The present study aimed to investigate the function of resveratrol in podocyte injury induced by ovariectomy and a HFD. The results revealed that resveratrol largely ameliorated obesity, hyperlipemia and insulin resistance in ovariectomized rats with an HFD. Notably, resveratrol significantly relieved podocyte injury $(\mathrm{P}<0.05)$, with a parallel decrease in inflammation-associated cytokines in these rats.

Obesity is mainly caused by white adipose tissue accumulation, and it affects the whole body through the release of pro-inflammatory cytokines, chemokines and adipokines (32).
Obesity is also considered to be a chronic low-grade inflammatory state. It has been confirmed that inflammatory responses and oxidative stress are able to be activated in obese rats induced by ovariectomy (33) or a HFD, which results in proteinuria, glomerular hypertrophy and renal dysfunction (30). In the present study, it was demonstrated that the level of serum E2 was significantly decreased in ovariectomized rats compared with those not treated with an ovariectomy $(\mathrm{P}<0.05)$, while an ovariectomy combined with a HFD induced marked obesity characterized by weight gain, hypercholesterolemia, hyperinsulinemia and insulin resistance. This indicated that the obese rat model had been successfully developed, though there were no differences in terms of serum TG and SCr levels in the four groups. It was also revealed that an ovariectomy in addition to a HFD promoted an increase in the levels of proinflammatory cytokines in the kidney tissue, including TNF- $\alpha$, IL-6 and MCP-1, which are generally produced by macrophages infiltrating adipose tissue. This result suggested that a renal inflammatory response was activated in the rats treated with ovariectomy and an HFD, which may further aggravate podocyte injury. This result was consistent with a previous study by Tang et al (34).

It has been demonstrated that the body initiates abnormal inflammatory responses during the menopause (35), and the primary inflammation is amplified in postmenopausal women with obesity (9). All these changes may affect renal function and structure, in particular podocyte injury. Furthermore, an increase in body weight and abdominal fat, and altered renal function and structure, have been observed in rats fed with a HFD for 24-weeks in addition to an ovariectomy (11). However, no significant renal functional, structural or pathological changes were observed in the experimental groups in the present study, potentially due to the short observation period. In the present study, the animals were observed for 12 weeks to investigate very early-stage obesity-associated kidney disease prior to the occurrence of renal functional and structural change. Regretfully, the present study did not set an ovariectomy combined standard diet group as another control, which is a limitation of the present study.

Nephrin, as a specific marker of podocytes, is crucial for slit diaphragm and foot process formation. A decline in nephrin 

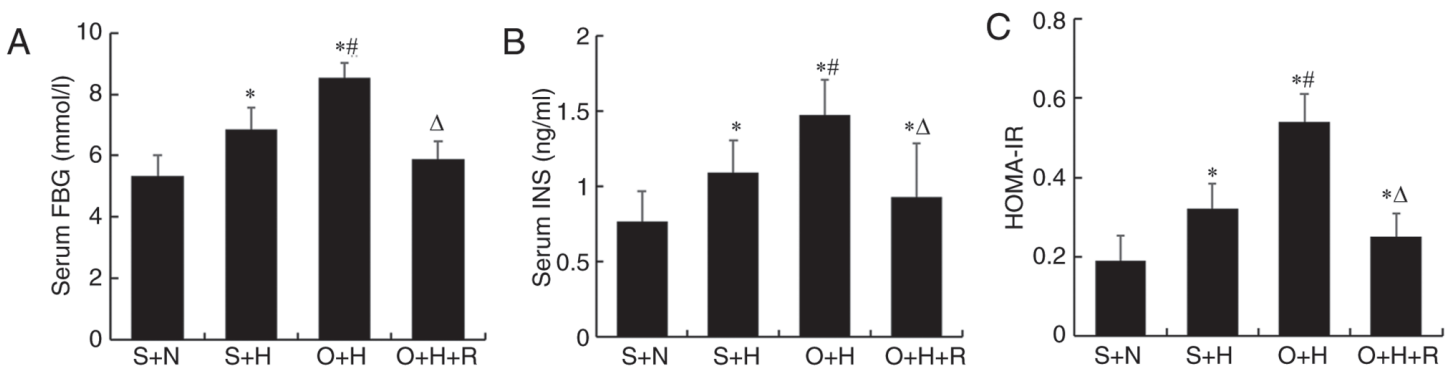

Figure 2. Effect of resveratrol on metabolic parameters in obese rats, evaluated by testing serum FBG and insulin and calculating the HOMA-IR. (A) Serum FBG, (B) insulin levels and (C) HOMA-IR in different treatment groups of rats. Data were presented as the mean \pm standard deviation (n=7-9 per group). $\mathrm{S}+\mathrm{N}$, sham-operation with standard diet, $\mathrm{S}+\mathrm{H}$, sham-operation with high-fat diet, $\mathrm{O}+\mathrm{H}$, ovariectomy with high-fat diet, $\mathrm{O}+\mathrm{H}+\mathrm{R}$, ovariectomy plus high-fat diet treated with resveratrol; FBG, fasting blood glucose; HOMA-IR, homeostasis model assessment of insulin resistance; INS, insulin. * $<<0.05$ vs. $\mathrm{S}+\mathrm{N}$ group, ${ }^{\#} \mathrm{P}<0.05$ vs. $\mathrm{S}+\mathrm{H}$ group, ${ }^{\Delta} \mathrm{P}<0.05$ vs. $\mathrm{O}+\mathrm{H}$ group.
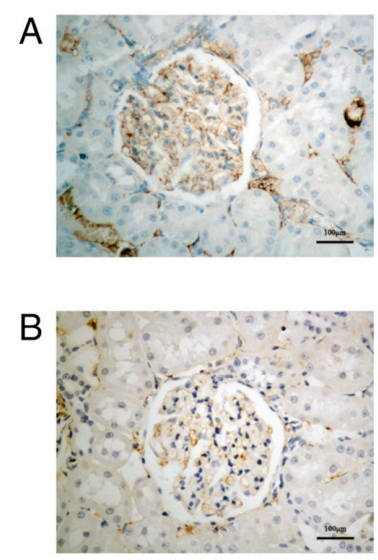

$\mathrm{S}+\mathrm{N}$
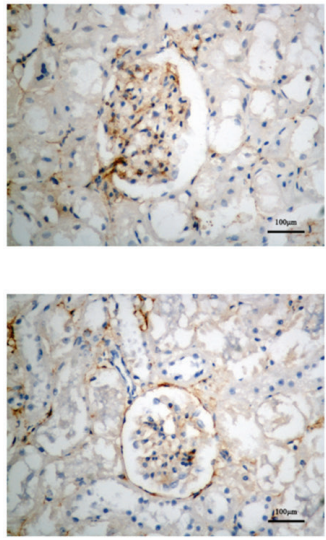

$\mathrm{S}+\mathrm{H}$
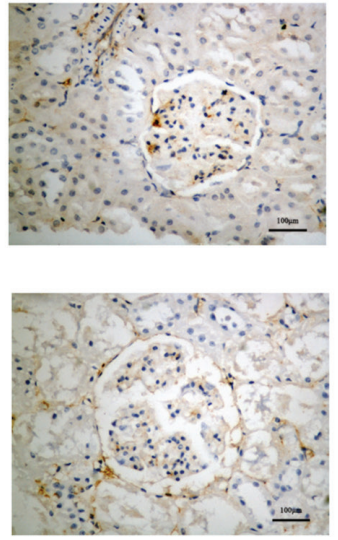

$\mathrm{O}+\mathrm{H}$
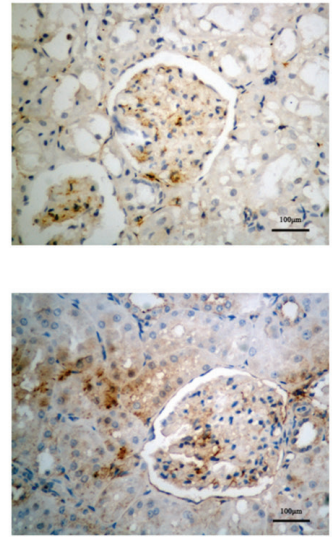

$\mathrm{O}+\mathrm{H}+\mathrm{R}$

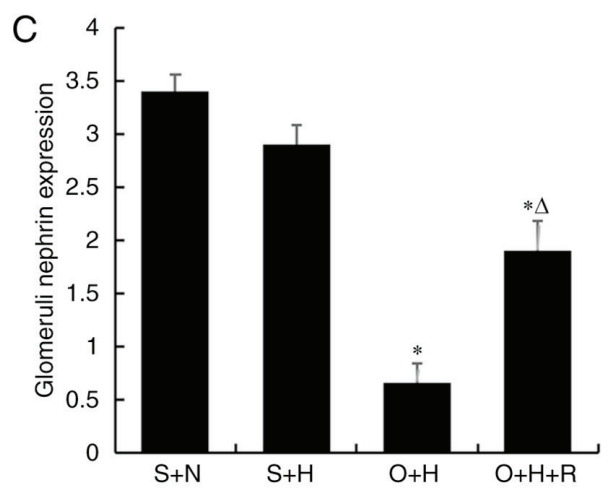

D

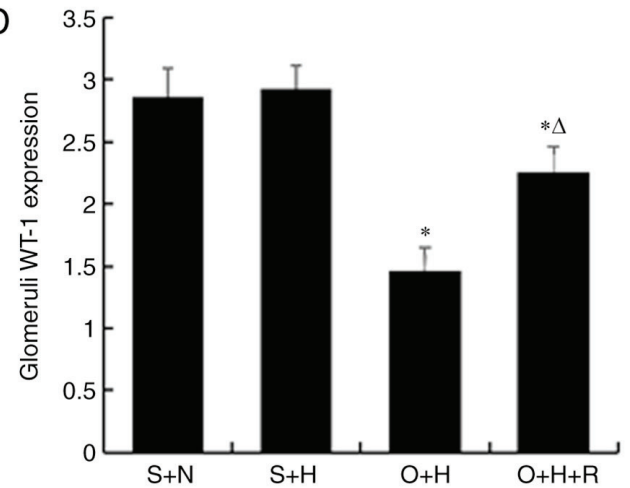

Figure 3. Immunohistochemical staining for (A) nephrin and (B) WT-1 in glomeruli (magnification, $\mathrm{x} 400$; scale bar: $100 \mu \mathrm{m}$ ). Semiquantitative analysis for (C) nephrin and (D) WT-1. Data were presented as the mean \pm standard deviation ( $\mathrm{n}=7-9$ per group). S+N, sham-operation with standard diet, $\mathrm{S}+\mathrm{H}$, sham-operation with high-fat diet, $\mathrm{O}+\mathrm{H}$, ovariectomy with high-fat diet, $\mathrm{O}+\mathrm{H}+\mathrm{R}$, ovariectomy plus high-fat diet treated with resveratrol; WT-1, Wilms tumor-1. ${ }^{*} \mathrm{P}<0.05$ vs. $\mathrm{S}+\mathrm{N}$ group, ${ }^{\Delta} \mathrm{P}<0.05$ vs. $\mathrm{O}+\mathrm{H}$ group.

expression and molecular damage will result in morphological changes in podocytes, the widening and fusion of the foot process, and subsequently leakage of plasma proteins $(36,37)$. WT-1, a transcription factor for nephrin, serves an important function in maintaining the phenotypic and functional status of glomerular podocytes (38). Meanwhile, changes in WT-1 expression are consistent with changes in nephrin (31). Therefore, the present study detected early podocyte injury by examining the expression of nephrin and WT-1. The present results demonstrated that nephrin and WT-1 were significantly reduced in ovariectomized rats with HFD compared with the sham operation and standard diet group $(\mathrm{P}<0.05)$, suggesting that podocyte injury had occurred in ovariectomized rats with HFD.

Resveratrol may be regarded as a phytoestrogen, owing to its similarity to diethylstilbestrol (a synthetic estrogen). It is able to regulate lipid metabolism, and alleviate renal damage through antioxidation and the inhibition of inflammatory factors (30). Previous evidence supports the theory that resveratrol not only improves insulin sensitivity and metabolic parameters, but also exhibits potential anti-inflammatory activity in renal mesangial cells by influencing the p38 mitogen-activated protein kinase 


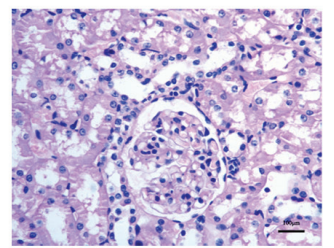

$\mathrm{S}+\mathrm{N}$

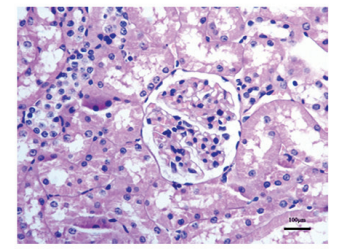

$\mathrm{S}+\mathrm{H}$

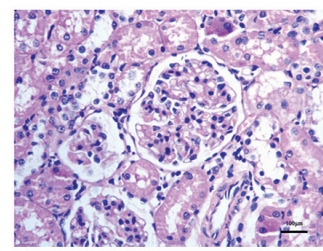

$\mathrm{O}+\mathrm{H}$

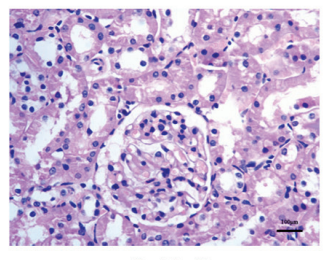

$\mathrm{O}+\mathrm{H}+\mathrm{R}$

Figure 4. Light microscopic examination of sections stained with periodic acid-Schiff. Magnification, $\mathrm{x} 400$; scale bar: $100 \mu \mathrm{m}$. S+N, sham-operation with standard diet, $\mathrm{S}+\mathrm{H}$, sham-operation with high-fat diet, $\mathrm{O}+\mathrm{H}$, ovariectomy with high-fat diet, $\mathrm{O}+\mathrm{H}+\mathrm{R}$, ovariectomy plus high-fat diet treated with resveratrol.

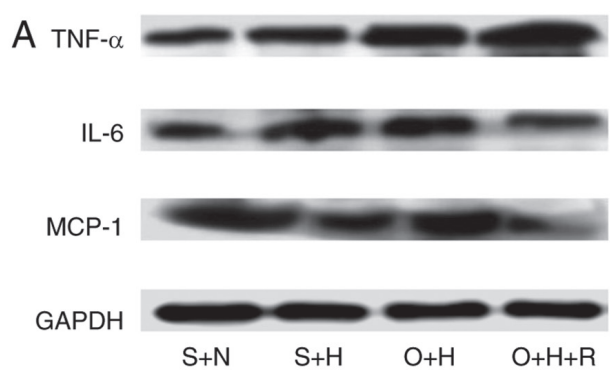

C

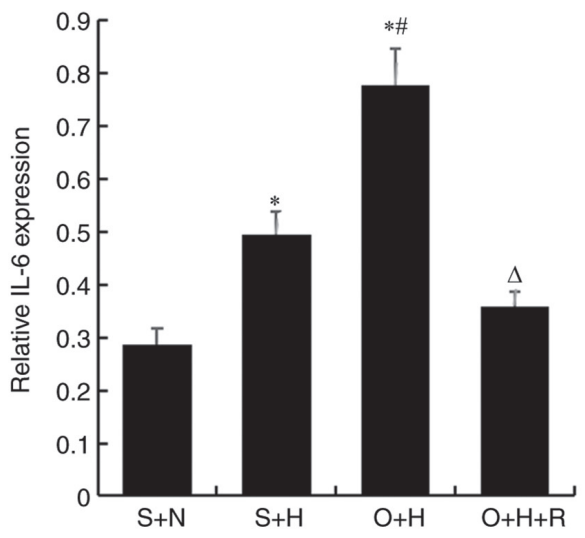

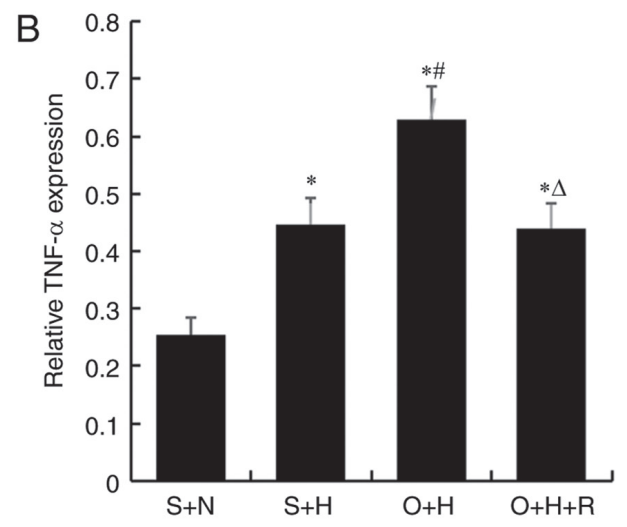

D

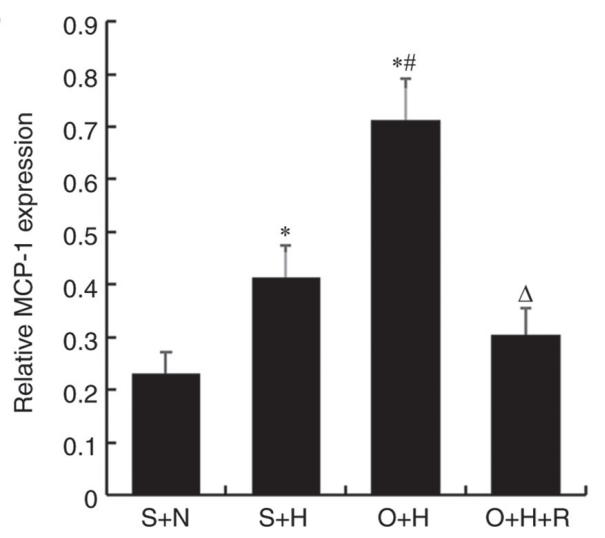

Figure 5. TNF- $\alpha$, IL-6 and MCP-1 expression in groups of rats with varying treatment types. (A) Representative TNF- $\alpha$, IL-6 and MCP-1 expression assessed using western blotting. Quantified protein values were calculated as a ratio of (B) TNF- $\alpha$, (C) IL-6 and (D) MCP-1 protein to GAPDH. Data were presented as the means \pm standard deviation ( $\mathrm{n}=7-9$ per group). $\mathrm{S}+\mathrm{N}$, sham-operation with standard diet, $\mathrm{S}+\mathrm{H}$, sham-operation with high-fat diet, $\mathrm{O}+\mathrm{H}$, ovariectomy with high-fat diet, $\mathrm{O}+\mathrm{H}+\mathrm{R}$, ovariectomy plus high-fat diet treated with resveratrol; TNF- $\alpha$, tumor necrosis factor $\alpha$; IL-6, interleukin 6; MCP-1, monocyte

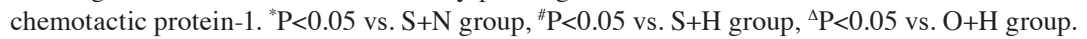

signaling pathway (39). In the present study, it was revealed that resveratrol treatment for 12 weeks effectively upregulated the level of E2, decreased body weight, lowered serum cholesterol and FBG, and enhanced insulin sensitivity. However, one study identified that estrogen synthesis increased following 9 weeks of a high cholesterol diet in ovariectomized mice (40). In the report, Li et al (40) considered that the high cholesterol intake may facilitate the synthesis of sex steroid hormones in the non-gonadal organs/tissues including the liver, skeletal muscle and adrenal gland in addition to the brain, and in turn, partially reverse serum sex hormone declines following a bilateral ovariectomy. Therefore, it was hypothesized that resveratrol may be have a similar effect in rats with ovariectomy and HFD. The specific underlying mechanism requires further study. The results of the present study suggest a functional role for resveratrol in the control of body weight and glycolipid metabolism in ovariectomized rats fed an HFD, consistent with previous report (33). The overexpression of the inflammatory factors TNF- $\alpha$, IL- 6 and MCP-1 in the kidney tissue was also reversed significantly after resveratrol treatment, suggesting that resveratrol exerts certain renoprotective effects in postmenopausal obese model rats. Resveratrol was shown to have marked protective effects on podocytes in $\mathrm{db} / \mathrm{db}$ mice and on cultured human podocytes through the stimulation of autophagy in a previous study (41). Another recent study also proved that resveratrol ameliorated podocyte injury and proteinuria in obese rats through suppression of the NF- $\mathrm{BB}$ signaling pathway, which initiates transcription and protein expression, including TNF- $\alpha$, IL-6 and MCP-1, resulting in substantial inflammatory responses (30). Notably, resveratrol treatment significantly enhanced nephrin and WT-1 expression levels in ovariectomized rats with HFD compared with the sham operation and standard diet group $(\mathrm{P}<0.05)$ in the present study. These 
results indicated that resveratrol may alleviate podocyte injury and exert a renoprotective effect.

In conclusion, resveratrol improves lipid metabolism, improves insulin sensitivity and regulates renal inflammatory responses, and thereby modulates nephrin and WT-1 protein expression in obese rats. Resveratrol serves a critical and novel function in the amelioration of podocyte injury in obese rats induced by ovariectomy and an HFD. The present study suggested that resveratrol may be used as a promising agent for obesity-associated early renal damage.

\section{Acknowledgements}

Not applicable.

\section{Funding}

The present study was supported by the Natural Science Foundation of Shandong Province (grant no. ZR2014HM037), the Science \& Technology Development Program of Jinan (grant no. 201401241) and the Key Research and Development Project of Shandong Province (grant no. 2017GSF21116).

\section{Availability of data and materials}

All data generated or analyzed during this study are included in this published article.

\section{Authors' contributions}

$\mathrm{BL}, \mathrm{XYX}, \mathrm{BJ}$ and $\mathrm{ZH}$ participated in the conception and design of the study, data analysis interpretation and drafting of the manuscript. BL, YLM, LG and XHL contributed to the data acquisition and analysis. JHZ collected and analyzed the pathological data. BL and XYX participated in the drafting of the manuscript and substantive revisions of the important content of the manuscript. All authors read and approved the final manuscript.

\section{Ethics approval and consent to participate}

The present study was ethically approved by the Animal Ethics Committee of Shandong University (Shandong, China).

\section{Patient consent for publication}

Not applicable.

\section{Competing interests}

The authors declare that they have no competing interests.

\section{References}

1. Finucane MM, Stevens GA, Cowan MJ, Danaei G, Lin JK, Paciorek CJ, Singh GM, Gutierrez HR, Lu Y, Bahalim AN, et al: National, regional, and global trends in body-mass index since 1980: Systematic analysis of health examination surveys and epidemiological studies with 960 country-years and $9 \cdot 1$ million participants. Lancet 377: 578-586, 2011.

2. Xu H: Obesity and metabolic inflammation. Drug Discov Today Dis Mech 10: e21-e25, 2013.
3. Hsu CY, Iribarren C, McCulloch CE, Darbinian J and Go AS: Risk factors for end-stage renal disease: 25 -year follow-up. Arch Intern Med 169: 342-350, 2009.

4. Morandi A and Maffeis C: Urogenital complications of obesity. Best Pract Res Clin Endocrinol Metab 27: 209-218, 2013.

5. Kastarinen M, Juutilainen A, Kastarinen H, Salomaa V, Karhapaa P, Tuomilehto J, Gronhagen-Riska C, Jousilahti P and Finne P: Risk factors for end-stage renal disease in a community-based population: 26-year follow-up of 25,821 men and women in eastern Finland. J Intern Med 267: 612-620, 2010.

6. Gambacciani M, Ciaponi M, Cappagli B, Benussi C, De Simone L and Genazzani AR: Climacteric modifications in body weight and fat tissue distribution. Climacteric 2: 37-44, 1999.

7. Burns KA and Korach KS: Estrogen receptors and human disease: An update. Arch Toxicol 86: 1491-1504, 2012.

8. Sayakhot P, Vincent A, Deeks A and Teede H: Potential adverse impact of ovariectomy on physical and psychological function of younger women with breast cancer. Menopause 18: 786-793, 2011.

9. Chedraui P, Escobar GS, Ramírez C, Pérez-López FR, Hidalgo L, Mannella P, Genazzani A and Simoncini T: Nitric oxide and pro-inflammatory cytokine serum levels in postmenopausal women with the metabolic syndrome. Gynecol Endocrinol 28: 787-791, 2012.

10. Mercantepe T, Unal D, Selli J, Mercantepe F, Unal B and Karabiyik TN: Protective effects of estrogen and bortezomib in kidney tissue of post-menopausal rats: An ultrastructural study. Ren Fail 38: 1129-1135, 2016

11. Amaral LS, Silva JA, Trindade TM, Ribas WB, Macedo CL, Coimbra TM, Belo NO, Magalhaes AC and Soares TJ: Renal changes in the early stages of diet-induced obesity in ovariectomized rats. Physiol Res 63: 723-732, 2014.

12. Meydani M and Hasan HS: Dietary polyphenols and obesity. Nutrients 2: 737-751, 2010.

13. Nagao K, Jinnouchi T, Kai S and Yanagita T: Effect of dietary resveratrol on the metabolic profile of nutrients in obese OLETF rats. Lipids Health Dis 12: 1-6, 2013.

14. Chen DQ, Hu HH, Wang YN, Feng YL, Cao G and Zhao YY: Natural products for the prevention and treatment of kidney disease. Phytomedicine 50: 50-60, 2018.

15. Chen DQ, Feng YL, Cao G and Zhao YY: Natural products as a source for antifibrosis therapy. Trends Pharmacol Sci 39: 937-952, 2018.

16. Hu HH, Chen DQ, Wang YN Feng YL, Cao G, Vaziri ND and Zhao YY: New insights into TGF- $\beta /$ Smad signaling in tissue fibrosis. Chem Biol Interact 292: 76-83, 2018.

17. Wang M, Chen DQ, Chen L, Cao G, Zhao H, Liu D, Vaziri ND, Guo Y and Zhao YY: Novel inhibitors of the cellular renin-angiotensin system components, poricoic acids, target Smad3 phosphorylation and $\mathrm{Wnt} / \beta$-catenin pathway against renal fibrosis. Br J Pharmacol 175: 2689-2708, 2018.

18. Feng YL, Chen DQ, Vaziri ND, Guo Y and Zhao YY: Small molecule inhibitors of epithelial-mesenchymal transition for the treatment of cancer and fibrosis. Med Res Rev, 2019 (Epub ahead of print).

19. Chen L, Yang T, Lu DW, Zhao H, Feng YL, Chen H, Chen DQ, Vaziri ND and Zhao YY: Central role of dysregulation of TGF- $\beta /$ Smad in CKD progression and potential targets of its treatment. Biomed Pharmacother 101: 670-681, 2018.

20. de la Lastra CA and Villegas I: Resveratrol as an anti-inflammatory and anti-aging agent: Mechanisms and clinical implications. Mol Nutr Food Res 49: 405-430, 2005.

21. Xia N, Daiber A, Forstermann U and Li H: Antioxidant effects of resveratrol in the cardiovascular system. Br J Pharmacol 174: 1633-1646, 2017.

22. Zhu Y, Feng B, He S, Su Z and Zheng G: Resveratrol combined with total flavones of hawthorn alleviate the endothelial cells injury after coronary bypass graft surgery. Phytomedicine 40: 20-26, 2018.

23. Huo X, Zhang T, Meng Q, Li C and You B: Resveratrol effects on a diabetic rat model with coronary heart disease. Med Sci Monit 25: 540-546, 2019.

24. Fulda S: Resveratrol and derivatives for the prevention and treatment of cancer. Drug Discov Today 15: 757-765, 2010.

25. Jeon BT, Jeong EA, Shin HJ, Lee Y, Lee DH, Kim HJ, Kang SS, Cho GJ, Choi WS and Roh GS: Resveratrol attenuates obesity-associated peripheral and central inflammation and improves memory deficit in mice fed a high-fat diet. Diabetes 61: 1444-1454, 2012 
26. Tsai CC, Tey SL, Lee MC, Liu CW, Su YT and Huang SC: Mechanism of resveratrol-induced relaxation of the guinea pig fundus. Phytomedicine 43: 55-59, 2018.

27. Kim S, Jin Y, Choi Y and Park T: Resveratrol exerts anti-obesity effects via mechanisms involving down-regulation of adipogenic and inflammatory processes in mice. Biochem Pharmacol 81: 1343-1351, 2011

28. Tou JC: Resveratrol supplementation affects bone acquisition and osteoporosis: Pre-clinical evidence toward translational diet therapy. Biochim Biophys Acta 1852: 1186-1194, 2015.

29. Alberdi G, Rodríguez VM, Miranda J, Macarulla MT, Arias N, Andrés-Lacueva C and Portillo MP: Changes in white adipose tissue metabolism induced by resveratrol in rats. Nutr Metab (Lond) 8: 29, 2011.

30. Pan QR, Ren YL, Zhu JJ, Hu YJ, Zheng JS, Fan H, Xu Y, Wang G and Liu WX: Resveratrol increases nephrin and podocin expression and alleviates renal damage in rats fed a high-fat diet. Nutrients 6: 2619-2631, 2014.

31. Kato T and Mizuno S: Nephron, Wilms' tumor-1 (WT1), and synaptopodin expression in developing podocytes of mice. Exp Anim 66: 183-189, 2017.

32. Zagotta I, Dimova EY, Debatin KM, Wabitsch M, Kietzmann T and Fischer-Posovszky P: Obesity and inflammation: Reduced cytokine expression due to resveratrol in a human in vitro model of inflamed adipose tissue. Front Pharmacol 6: 79, 2015.

33. Sharma R, Sharma NK and Thungapathra M: Resveratrol regulates body weight in healthy and ovariectomized rats. Nutr Metab (Lond) 14: 30, 2017.

34. Tang J, Yan $\mathrm{H}$ and Zhuang S: Inflammation and oxidative stress in obesity-related glomerulopathy. Int J Nephrol 2012: 608397, 2012.

35. Abu-Taha M, Rius C,Hermenegildo C, Noguera I,Cerda-Nicolas JM, Issekutz AC, Jose PJ, Cortijo J, Morcillo EJ and Sanz MJ: Menopause and ovariectomy cause a low grade of systemic inflammation that may be prevented by chronic treatment with low doses of estrogen or losartan. J Immunol 183: 1393-1402, 2009.
36. Brunskill EW and Potter SS: Changes in the gene expression programs of renal mesangial cells during diabetic nephropathy. BMC Nephrol 13: 70, 2012.

37. Batlle D, Wysocki J, Soler MJ and Ranganath K: Angiotensin-converting enzyme 2: Enhancing the degradation of angiotensin II as a potential therapy for diabetic nephropathy. Kidney Int 81: 520-528, 2012.

38. Kalani A,Mohan A, Godbole MM, Bhatia E, Gupta A, Sharma RK and Tiwari S: Wilm's tumor-1 protein levels in urinary exosomes from diabetic patients with or without proteinuria. PLoS One 8: e60177, 2013.

39. Matoba K, Kawanami D, Ishizawa S, Kanazawa Y, Yokota T and Utsunomiya K: Rho-kinase mediates TNF- $\alpha$-induced MCP-1 expression via p38 MAPK signaling pathway in mesangial cells. Biochem Biophys Res Commun 402: 725-730, 2010.

40. Li L, Xiao N, Yang X, Gao J, Ding J, Wang T, Hu G and Xiao M: A high cholesterol diet ameliorates hippocampus-related cognitive and pathological deficits in ovariectomized mice. Behav Brain Res 230: 251-258, 2012.

41. Huang SS, Ding DF, Chen S, Dong CL, Ye XL, Yuan YG, Feng YM, You N, Xu JR, Miao H, et al: Resveratrol protects podocytes against apoptosis via stimulation of autophagy in a mouse model of diabetic nephropathy. Sci Rep 7: 45692, 2017

This work is licensed under a Creative Commons Attribution-NonCommercial-NoDerivatives 4.0 International (CC BY-NC-ND 4.0) License. 